favorel. It was hoperl at one time that the tempera- in ture of the joint could be recised sufliciently to inhibit the growth of the genococcus, which is very suscep)tible to heat. 'This seems not to be the casce. Flaming with the actual cautery is the lest comberirutant and often relieves the pain.

$\Lambda$ lssolute immolilization by appropriate splints is the best treatment in the acute stage. $\Lambda$ s in other forms of arthritis, flexion of the knee may oceur early. If gradual extension is too painful, an ancsthetic: should be given at once, and the joint straightened and immolilized, for if anchylosis results alhesions can be more safely broken by flexion that by extension. In the ellow the opposite is true, and this joint should be flexed to a right angle.

While the acute process usually sul,sides within two or three weeks, in many cases great pain follows attempts at motion, probably due to the rapiel formation of allhesions within and ahout the joint. Ilere the physician is at a loss to decide upon the proper treatment. 'The joint grows stiffer day by day, yet movement is bitterly complained of by the patient. In such cases, advantauge should be taken of the period of diminished sensitiveness to pain which usually follows the hot-air bath. Massiage should precede movement. Linless the signs in the joint become worse, treatment should be firmly persisted in. $\Lambda \mathrm{t}$ intervals, under an ancsthetic, the joint may be once fully flexed and extended, allowed to rest for a couple of days, when active and passive movements should be continned. In the acute stages. when the eapsule is much distended, aspiration should be done for the purposes of diagnosis, and irrigation of the joint. In the subacute period the usually small amount of fluid is probably beneficial, separates the inflamed joint surfaces and prevents their adhesion. Pressure ivith immolilization should not be used at this time. The question of operation in gonorreal arthritis is coming more and more to the fore, and is alvocated even in relatively mild cases by good surgeons, who report numerous cases where the fever, general symptoms and pain have been quickly relieved by operation, and earlier use of the joint followed.

By operation the toxins and gonococei in the joint fluid may be rapidly evacuated, and such treatment is indicated in all severe gonorleneal joints, as in any septic arthritis. With proper precantions the clanger from sepsis is probalnly slight in comparison with the alvantage to be gained; good temporary results may follow operation in the knee, where the surfaces can be secu, thoroughly clemer, and supesficially disinfected; but, as the gonococei will continue to proliferate in the symovial membrane beyond reach, the process, though ehecked, will often continue. $\Lambda$ s relatively few pure gonorlical infections leal to suppurat tion, the treatment by immobilization and early passive motion is safer for general aloption. J'articularly is this true in the more complicated joints, as the ellow, ankle or wrist, where thorough irrigation and drainage are ustally impossible, and where incisions among the aljacent tendons would not infrequently lead to the anchylosis which operation is intended to prevent. When pus can be demonstrated by fluctuation, edema and rechess, or aspiration of the joint or tendon sheaths, then only should operation be resorted to. Incision, irrigation, immediate suture, without drainage, should be attompterl.

The passive hyperemia mothod, advocated by Behr, in the treatment of joint tuberenlosis, has heen used with good results in gonorlheal arthritis. The limb is batulaged "p to the joint; above it a flat tourniquet is applied, sulliciently tight to impede the venous circulation. The joint swells, the pain is relieved, and earlier motion is reported. This was true in 2 of my cases. In 3 other's no benefit followed.

SUMNRY.

In this paper I have endeavored to show: (1) 'That the gronococens alone can cause arthritis, which, withont the presence of other organisms, mat be purulent.

(2) (Aonomheal arthritis oceurs not only in acute gonorlea, but in the chronic or latent staiges, which persist much lomger than is commonly believed.

(3) The sigus of such ehronic infection in the male and female are often slight, and dislegarded or overlookerl by the patient and physieian.

(4) In conserpence, not a small proportion of cases are diangnosed as articular rheumatism which are really of gonorrheal origin.

\section{NEUROPA'THIC JOIN'TS.*}

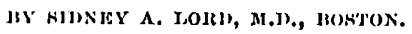

I'r is obvious that the term "neuropathic joint" might reasonably be of very wide or extremely limited application, according to whether we had most in mind the fundamental rôle played by the nervous system in all vital processes on the one hand, or on the other the smallness of the number of joint affections generally regarded as essentially trophic in nature.

I shall apply the term in this paper to all those affections which seem, from the evidence at present available, to owe their characteristics to the direct influence of the nervous system, whether strictly trophic or not. The limitations of time will prevent any more than passing mention of the neuromimetic and so-called hysterical joints, which indeed do not fall within my province, for they depend upon disorder of ideas, are psychopathic in origin, not resulting from physical lesion. 'They have moreover but slight bearing on the differential diagnosis of the profoundly altered joints with which this paper principally deals.

Taking up first the classic examples of true nervous arthropathies as they are called - those of tabes dorsalis and syringomelia - we find that the anatomical characters are almost identical in the joints, notwithstanding the great and essential differences shown by the discases as a whole, so that much of what can be said of ono applies to both.

It is of primary importance to recognize the facts that the joint lesions of these two cord diseases are in typical form almost absolutely limited to them, that they occur with frequency, $5 \%$ to $10 \%$ of all tabetics and about $10 \%$ of syringomyelics being thus affected, and that conspicuons among the symptoms in both troubles are extensive losses of sensation. The course of these arthropathies need not be here described in great detail.

Tho following mode of onset is not at all uncommon. Entirely without warning, entirely without pain, entirely without evident cause, during some mild * Tead bofore 'Ihe Massachusetta Modical Socioty, Jume 13, 1900,
and rocommonded for publication by the socioty. 
muscular action, absolutely without effort, often quite before any development of ataxia, the leg gives way or the arm drops, and the joint - knee or shoulder, for example - becomes at once useless; or if not at once, in a few minutes or hours. For there quickly ensues an enormous, tense, fluctuant swelling, utterly destroying action of the joint. In its suddenness and extent, this swelling is quite out of the domain of all other conditions besides tabes or syringromyelia, except that following the great crushing violence of accident cases. 'The swelling extends usually beyond the joint limits - this is very characteristic; in fact it is not uncommon for the whole limb, or one segment, to increase enormously in size with astonishing rapidity. 'The cause of this is a rematkable subcutancous and muscular intiltration, hard, non-pitting, of ten visibly hemorrhagic. 'There is no pain, and signs of inflammation are absent.

'The further course of these arthropathies is the reverse of the onset: absorption is slow and rarely complete, there remaining permanently moderate hydrops, with eventual (sometimes extremely rapid) development of flail joint or Schlotter-gelenk, a unique condition of painless, fully mobile luxation. 'This state of abnormal mobility does not necessarily require a long time for its production - it may often be detected to slight degree in the course of a very lew weeks, or as soon as the swelling has considerably receded. During the stage of active distention, it is not usually present. 'The extreme grades of it, resulting in those fintastic shapes which, as Marie' says, "shame the doublejointed man" and result even in perforation, are only found in chronic cases. After this stage there sometimes occurs complete restitutio ad integruin, not withunt tendency to relapse, however. 'There commonly remains grating on movement, and the neighborhood of the joint slowly enlarges. 'Termination in anchylosis is rare. (Schlesinger 2 reports 2 cases in syringowyelia.) Other than this, cure is not to be expected.

The pathologic anatomy of these lesions is most interesting. It resembles much that in arthritis deformans, and consists in rarefication and hypertrophy of bone, cartilacre, ligament, and synovial membrane. Combinations of these changes are most diverse, and explain the clinical variations in large degree. Bony frangibility and weakness of ligaments are of especial importance.

'There are two principal types of change - atrophy and hypertrophy. In the atrophic form thero is sometimes immense absorption of bone, which may include a considerable part of the shaft, - of the humerus or femur, for example, - the heads of the bones having completely disappeared. The opposing bony joint surface is likely to become somewhat liypertrophied under the influence of abnormal attrition. The hip and shoulder usually show the atrophic form.

The hypertrophic form is more common; there are irregular bony projections, perhaps free pieces of bone, large and small, in the joint, the cavity of which looks shrunken, through tho great development of comnective tissue. In the middle of tho joint the cartilagge has disappeared. The fluid in the joint is thick, yellow, sometimes hemorrhagic, occasionally almost pure blood. 'The ligaments aro destroyed and ossified in varying degrees. The synovial nembrane is often luxuriantly fringed. Fracture into the joint is com- mon. 'This last statement indicates that there is an extreme degree of bony fragility ; in arthritis deformans such fracture, at least of the whole head of the bone, as is here seen is alosent or extremely rare. Anatomically still other distinctions between the two conditions have been described.

What is the immediate cause of these arthropathies? In discussing this it will be important to mention the chief elinical variations. It is vital to point out that, in its etiology, it is impossible to separate fracture from the arthropathies themselves. 'There can be no loubt of very frequent coincidence of fracture with arthropathy; and in the joints above discussed, with large swellings, the relation is probably nearly constant. I believe it highly probable that in such cases the fluid is, much more commonly than at present supposed, purely the result of active hemorrhage. Brissaud's ${ }^{8}$ interesting case illustrates this. Tapping is unfortunately rarely done, so that we can. not bo sure.

It seems to me that this factor of hemorrhage is necessary to complete the theories of Paget, Volkmann, Kolisko and others who believed that the whole cause of arthropathy lay in violent ataxic movements, suflicient to fracture bones and to rupture the joint structures. The great foree of these unfelt inco-ordinated movements, the inco-ordination being angmented sometimes by irregular muscular atrophy, must be acknowledged, and the potency of this cause admitted, in view of the oceurrence of so-called spontaneous fracture of even thick and selerotic tabetic bones (Kolisko). It is easily seen that joint hemorrhage would be highly spt to result from such violence, would be rendered even more likely by the erosion of soft structures, and would explain particularly well the rapidity of swelling. 'There is, further, special around to suspect hemorrhatge when, as very rarely happens, much pain exists (Brissaud).

But ataxia, if a factor in producing these arthropathies, is not their exclusive cause. For, how would it account for their appearance in syringromyelia, in which there is no ataxia, or in tabes before the development of ataxia, or for their following exceedingly slight direct blows? (Or, how would it explain the enormously diffused serous infiltration (not explainable mechanically), or the progression of symptoms during quietude, and the continuance of hone atrophy when the articular surfaces are no longer in contact?

It is evident that the final cause of these arthropathies is other than the immediate mechanical influence of ataxial, and that a more subtle pathology is demanded.

Arthritis deformans, gont and syphilis, all of which have been widely believed in, and strenuously put forwaril as exclusive causes, will, it is obvious, not begin to account for the extraordinary phenomena just described, nor will they account for the milker forms of arthropathy which their manifestations much more resemble, for those milder forms pass finally into severe ones. (Striimpell," formerly skeptical, now admits that it is hard to avoid the assumption of trophic disturbance.)

The association of these arthropathies with tabes and syringomyelia in some perfectly definite way is quite evident - their rarity in other cord diseases points to this - likewise the large number of othor 
phenomena of undoubted trophic origin in tabes and syringomyelia; it seems in fact quite necessary to assume a special trophic disturbance, to account for the joint diseuse in question.

Is this trophic disorder due to neuritis? There is much evidence in favor of this, but not enough to warrint the assumption that neuritis is the only eituse. Its presence is not constant, though very frequent, as Pitres and Carrière ${ }^{0}$ have shown. We do not know whether it is secondary to the joint trouble, or whether it is due to the cord lesion. It is most intense in the neighborhood of the affected joint, and this points to the first possibility as the true one.

The following may be regarded as a conservative view: Several factors undoubtedly can and do exist in the etiology of both high and low graties of the arthropathies; but the only absolutely constant element is the nervous system, which acts directly by influencing nutrition, and indirectly by causing ataxia. These factors are, in the order of their probable importance, central and neuritic trophic disorder; anesthesia of the joints; traumatism, direct and (through ataxia) indirect; muscular hypotonia; arthritic tendency and syphilis. They act probably in this way. The nervous trouble predisposes the joints to disease through alteration of the sensory neurons. 'That the sensory nerves, while furnishing sensibility to the bones and joints, in some way take care of their nutrition may be regarded as proved. Now there is equal reason to suppose that normal synergetic muscle actions depend on continuous afflux of stimuli from the periphery. 'Therelore, any interruption of function of the centripetal joint nerves will result in inco-ordination, with consequent loss of normal support to the joint. This loss entails uneven and violent stretchings and pressures on the ligamentous structures and articular surfaces. The disorder increases in a viciuns circle on account of the relation between muscle and ligament. Osseous hyperplasia or atrophy oceurs, this being determined probably by increase or loss of blood supply from vasomotor changre. Irritation from rubbing is part of the cause of the exostoses. Latent arthritic tendencies, which, of course. must often be present, are hastened into activity, and pursue a more extended course than they would otherwise take. Continued use of the joint, on account of the alsence of all pain, after the lesion has begun, is a most important element in causing further damage. It must be added that the early inco-ordination which occurs on the development of joint anesthesia probably begins at once to damage the joint even before ataxia has been manifest. 'This helps to explain the excessively early appearance of some of these lesions. The rồle of hypotonia etiologically is likewise constant, if less important. That of syphilis may be deemed comparatively unimportant on account of the fact that there is nothing to show that the disease is frequently present.

In concluding this matter of etiology, the close and interesting correspondence of the arthropathies to the seat of the chief cord lesion must be mentioned localization in upper limb in syringomyelia, in the lower in tabes. On the contrary, when the gliosis is of the lumbar type the arthropathies affect the lower limbs. Cervical tabes in like manner has been asso. ciated with upper limb arthropathy. It is to be presumed that shoulder affections of tabes are always to be explained on the anatomical basis of cervical involvement, and that, in general, leg athropathies occur the earlier in tabes.

'The other joints affected in tabes are, beside the vertebra, nearly all the articulations, knee, hip, shoulder and elbow being the most freguently involved.

'The "tabetic foot" is of rather different type, showing constant tendency to hypertrophy of bone, including even tibia and fibula, and ending in anchylosis. Its sudden and painless begimning results from rarefication and crumbling of tarsal and metatarsal bones. 'The shape is unlike anything else; the foot looks shortened, thickened and rounded, and the vault has disappeared. The appearance known as Chinese foot is largely due to muscular atrophy (Senator ${ }^{7}$ ), and occurs in various other diseases. It must be distinguished from true tabetic foot.

In syringomyelia, the arthropathies of the small hand joints and the severe grades of kyphoscoliosis, all ascribed to trophic disorder, are worth mention. 'The purity of the type in the hand is obscured by infection and suppuration (Schlesinger).

'l'here are certain unusual events in the course of classic arthropathies, notably the very rare occurrence of pain, sometimes severe, ascribed by Brissaud wholly to stretching from effusion. It is, however, not wholly understood. It is possible that the usual rupture of the capsule, allowing escape of fluid and permeation of the periarticular tissues, here fails to occur. It is not clear why pain appears unless we assume analgesia of the joints but not of the skin. Investigation of possible association with neuritis would be of interest. 'The presence of pain has been adduced without justification, in my opinion, as an argument against the causative influence of analgesiat. Suppuration and inflammation are most uncommon and certainly obscure the type of tabetic joint when present. 'The pathology is obviously different from usual. Suppuration is almost invariably secondary to trauma, occurs in the late cases, and should not confuse. Its course is remarkably mild, and in general the reaction of these joints to infection is slight.

The diagnosis of these joint lesions is rarely difficult except in certain early casses not long under observation. Mistakes would almost never occur if the possibility of cord lesion wore in mind. Enough has been said to show the distinctions from simple fracture and luxation. 'There is, however, a condition of habitual luxation of the shoulder joint in syringomyelia, often preceded by direct trauma, which is of great practical and medico-legal importance. 'This may occur before obviously extensive change in the joint, and the patients have usually come to the surgeon unaware of central trouble. Schrader ${ }^{8}$ reports 15 cases. Some of these had had previously no cord symptoms.

Occasionally an early case with slow, chiefly hypertrophic changes, especially if tending towards anchylosis, will be confused with osteo-arthritis. The resemblance may be close clinically, but these cases are uncommon and rarely long unassociated with symptoms of the central lesion. There may be a history of unduo mobility. Characteristic involvement of small joints is lacking. There is also likely to be much more extensive periarticular and subcutaneous ossification than occurs in arthritis deiormans, and a greater liability in the presence of large, free, bony masses in the joint.

In those cases in which, like that of Dercum and 
Spiller ${ }^{\circ}$ (syr.), grating in the joint precedes by years the development of typical arthropathy, the diagnosis may at first be impossible.

'The extreme atrophic cases with luxations are unmistakable.

There have been reported anomalous conbinations of symptoms resembling both syringomyelia and tabes; the greater tendency in the former to diffuse ossificition in the limb and to necrosis of bone would assist in the diagnosis of any joint trouble.

'The complex of Morviun's disease, so called, is common to both leprosy and syringomyelia, and need not be further considered as such. Leprosy occasions dificulty only in hand aflections and only in atypical instances.

One case of central cord tuberculosis produced typical tabetiform arthropathy and was not diagnosed intra vilam (Schlesinger).

Hematomyelia, a coudition of hemorrhage into the cord in which the distribution of the blood is much like that of the gliosis process, appearing generally after accidents, may be in question. Ono doubtful case of this kind, that of Goldthwait, ${ }^{10}$ has come to my notice.

Syphilis must always be considered as a remote possibility, simulating perhaps more the foot affection than those of the other joints. Practically speaking, antispecific treatment never benefits these tronbles. When it does do so it might be expected that other luetic symptoms would be present; but this is not true, otherwise a suspicion would be warrantable that not tabes but spinal lues was the central lesion.

Londe ${ }^{11}$ calls attention to one case of true arthropathy in progressive muscular atrophy of the spinal type, and to one in chorea. He draws a fundumental distinction between the genuine lesions occurring in those diseases and gliosis and tabes, on the one hand, and all other nervons joint disorders on the other; asserting that, in the latter, one of two factors - infection or auto-intoxication - is always necessary for the production of the arthropathy, plus the nervous element. 'The nervous system is supposed to determine principally the location of the joint trouble in such cases, and Londe is right on the whole in thus assigning to it a subordinate part. 1 think, however, that two additions may be made to his list of diseases in which genuine arthropathics occur, to wit, central tuberculosis of the cord and certain instances of the trophic variety of intermittent hydrops, and perhaps hematomyelia.

'Those non-genuine arthropathies emphasized by Londe are seen most frequently and typically in myelitis, neuritis and hemiplegia, also have been reported in Friedreich's disease, ataxic paraplegia, bulbar paralysis, and tuberculosis of the spinal column. They are all rare, and occur with significant inconstancy compared to the regularity of joint involvement in tabes and gliosis. And it is to be observed that they are not associated so definitely with extreme scnsory losses as are tabes and gliosis.

'The false arthropathies, as they may be called, aro of quite different type from the genuine - they are distinctly inflammatory in nature, accompanied constantly by pain, redness, and often by suppuration.

In regard to those in hemiplegiil, Weir Mitchell ${ }^{12}$ has recently renewed attention to the intense irritativo - not paralytic - sensory symptoms, and deprecates the superficial reasoning which assumes a mere coincidence with rheunatism. These hemiplegic joint lesions are in most remarkable mamuer preceded, sometimes for years, by lively pains which are limited to the side afterwards paralyzed.

There are several other joint affections which may be spoken of as neuropathic. Among them the most interesting is hydrops articulorum imtermittens. About 35 examples have been reported; they represent several different pathological states, but a iter eliminating those cases in which some such obtrusive condition as acute osteomyelitis gives at least an anatomical basis for the disetse, if it does not aftord an explanation of the periodicity, there remians a group in which the regularly or irregularly recurring hy. drops, of apparently spontaneous beginining, is susceptible of no other explanation than that of vasomotor disturbance. Some of these are certainly hysterical. The location is far more commonly in the knee than elsewhere, but the other joints liave been affected. It is usually unilateral, sometimes alternating right and left, seldom very painful, and often quite irregular in its manifestations. The more striking calses are, however, almost uniform in recurrence, and in duration of attack and in location. The intervals vary from hours to montlis, but most frequently last from ten days to two weeks. 'The disease sometimes persists for many years, finally to cease spontaneonsly or seemingly through the influence of treatment. This trouble is rarely mentioned in the books. Among others, Senator ${ }^{18}$ has recontly written upon it and points out that the question of the presence of slight degrees of real inflanmation cannot be decided as long as we do not know the absolute distinction between exudate and transudate. $\Lambda$ n exceptionally well-marked case which I have lately seen will be made the subject of further report.

Another type of great interest is the acro-arthritis of Hutchinson, recently described further by MacMalion, ${ }^{14}$ regarded by the former as induced by grout in cases showing marked tendency to Reynaud's disease; that is, to conspicuous circulatory disturbance in the fingers. In this trouble the terminal finger articulations become typically wobble-jointed, with effusion, in tabetic fashion. 'The anatomicopathological appearances correspond to those in tabes, which, it must be remembered, may itself produce arthropathies in this location. 'Tabes, however, is not presont in Hutchinson's grroup.

The disease described by Marie as osteo-arthropathy of pulmonic origin is not an arthropathy to :my essential extent, and is better described as ossifying osteoperiostitis with hypertrophy of neighboring soft parts. It is usually of toxic origin, and oceurs in many other than lung diseases; although in those it develops the most acutely and to the highest degree.

Its essential lesion occurs in syringomyelia at times. Clinically, it begins with clubbing of the fingers, but the ordinary form of finger charricteristic of lung disease is accentuated into a marked drumstick type with enormous nails, which attain the full width of the phatlanx, leaving no marginal flesh. Decided or even cauliflower-like tufting of the bone shows constantly, in radiographs. When fully developed, this disense induces pronounced enlargement of wrists, ankles and adjacent parts of the long bones. It is uncommon. The photographs which I show you indicate the treedom of the joints from the affection.

In regard to the treatment of the trophic joint 
lesions, unfortunately only too little can be said. But it is certainly true that it has been unduly neglected. The outlook when the affection occurs in tabes or gliosis is undeniably bad; but can we not do a little more in prophylaxis? In all severe nervous troubles, particularly when extensive paralyses of sensation accompany them, every precaution should be taken to prevent violence to the joints. There should be constant watchfulness for grating or undue mobility; and with the first definite indication of approaching trouble in a joint, this watchfulness must be redoubled, and temporary rest in bed enjoined, with measures for immobilization. Relief of pressure from effusion must be secured in the event of tense swelling, by tapping. If done early in hemorrhagic cases the bleeding might be stopped by hemostatics, and the weakened joint structures saved from the destructive effects of great distention. Antispecific drugs should be given their slim clinnce in the beginning. The deleterious influences of ataxia should be guarded against by the early employment of Fraenkel's invaluable method of training.

The extreme forms of joint disorganization with dislocations must have orthopedic treatment; leather splints, properly applied, are very eflicacious. Amputation is sometimes advisable, and $I$ see in the peculiar state of trophic function no contraindication. $\Lambda \mathrm{s}$ a matter of fact, these joints and limbs heal readily. Indeed, it is often aflirmed that the union of fractured bones takes place with unusual speed, the large callus being held to corroborate this view. 'This is wrong. 'The repair of bone occupies generally as much time as usual, indeed sometimes obstinate non-union is seen. 'The great callus often observed is the result of continued attrition in the ataxic, analgresic member.

The inflammatory type of arthropathy is more amenable to treatment. Suppuration demands surgical measures. As has been pointed out, there is not here the menace to life associated with other forms of acute suppurative arthritis.

For intermittent hydrops, besides removal of obvious cause of inflammation, the use of arsenic in long continued moderate doses has seemed to be of much service. But in the purcly idiopathic variety our present crude methoils achieve little result.

\section{REFERENCES.}

1. Mario. Lecons sur les maladies de la moelle, 1892, No. 19. 2. Schlosinger. Monograph, Vienna, 1895, Dio Syringonyelio. 3. Brissand. Lecons, 1895 .

4. Kolisko. By Kofend, Wien. klin. Woch., 1898, S. 314.

b. Strüinpell. Spec. Path. u. Therap., 18!5.

6. Pitres ot Carrière. Arch. clin. de Bordeaux, 1896 ; references Journal of Nervous and Mental I)iseases, 18!18, p. 494.

7. Senator. Berlin. klin. Woclı., 18!)8, No. 2(9.

8. Sehrider. Beitr. zur klin. Chir., 1899, H. 1, S. 199.

g. Dercum and Spiller. Americau Jourual of Medical Sciences, December, 1896.

10. Goldthwait. 'Transactions of Amorican Orthopedic Association, 1892.

11. Londe. Nouvolle iconographie de la Salpêtrièro, 18!17, No.6; Ref. Centrbl f. Nerv, u. Psych. 1898.

12. Mitchell. Clinical Lessons, 1897.

13. Senator. Charité Anu., 18!66, Bd. xxi.

14. MacMaliou. Lancet, 1899, No. 3974, p. 1156.

Ambidexterity to be 'Taligit' in Pinhaderina Schools. - It is said that the Board of Education in Philadelphia is about to undertake to train school children to be ambidextrous through a regular course of exercises to be carried out at the schools. 'The success of the experiment will be watched with interest.

\section{THE BOSTON}

\section{ftretcal and Surgical $¥$ Jumual.}

\section{THURSDAY, OCTOBER $18,1900$.}

A Jourmal of Medirine, Surgery and Allied Sciens:es, published at Boston, weelily, lyg the undersigned.

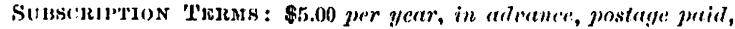
for the United states, Canada and Werico; $\$ 6.56$ juer year for all foreign conentries belonging to the P'ostal Union.

All communications for the Edlitor, and all bonls for veniew, shomld be addressed to the Editor of the Boston Mediral and surgical Journal, 283 Washington strest, Joston.

All letters containing business communications, or werring to the publication, subscription or adrertising depertment of this Journat. skould be addressed to the undersigned.

Remittances should be made by money-order, dratt or registered letter, payable to

DAMRETI, \& UPIIAM, 283 WASIINGTON S'TRIETT, JOSTON, MASS

$=$

\section{PLAGLE.}

Wirir the development of improved and more rapid means of communication, it is a self-evident fact that distant parts of the world are being brought into closer and closer relation, and the dangrer of the spread of discase thereby very greatly increased. 'Thirty years agro we had small fear of the introduction of tropical diseases into our large cities; now we must be constantly on our guard lest through some carelessness an infected vessel gain access to our ports and its crew be the possible source of the dissemination of disease. No more striking evidence of the acknowledgment of this new responsibility could be furnished than the success of the recently organized Isondon Sclsool of 'Tropical Medicine, which is already crowded with students in preparation for the intelligent study and treatment of diseases of the tropics. During the past months the danger of the introduction of disease from regrions where it is endemic has been strikingly sloown in the appearance of plague at various distant points in almost every part of the world. The fact that it has gained no headway is an equally strong proof of our increasing ability to cope with the large question of prophylaxis. 'The experience through which Glasgow has gone with regard to plague, and its gratifying outcome, is an object lession which we should fo well to ponder. In the October number of the Srottish Medical and Suryical Journal, Dr. W. Leslie Mackenzie, medical officer of health, narrates certain matters of interest with regard to the situation in that city. However stringent a quarantine may be, he feels that the spread of the disease is usually brought about by the mild, unrecognized ambulant case, which means vigilance far greater than is necessary to comply with ordinary quarantine requirements. Furthermore, the rats and fleas must be exterminated, a task apparently of no small magnitude. So far no really successful method has been found. Dr. Mackenzic concludes his very vigrorous paper as follows: "The public confidence in Glasgow vigilance and energy 